OYSTERS, OYSTER FISHING. AND OYSTER CULTURE AT THE FISHERIES EXHIBITION

$\mathrm{A} S$ long as the English "native" keeps its prominent A place in the market all questions concerning oysters and oyster culture will have a special interest for the British public at large. For the man of science oysters are none the less interesting, although from a different point of view. For him it is a great puzzle that up to row we are in so profound a state of ignorance concerning certain of the most important phases of life of a mollusk so exceedingly numerous, which may indeed be called very common, if not always plentiful, all along a large extent of the European coast. Questions such as the following:-Are oysters functional hermaphrodites or not? At what age can oysters reproduce their species? How long do the oyster larvæ (the so-called "spat") swim about in the ocean as free and independent, although minute, living specks? What is the effect of currents and temperature, both upon the growth and upon the fertility of the oyster? are or were up to very lately wholly unsolved, and no really scientific inquiry had thrown any definite light upon them. Even the anatomy of the oyster was very imperfectly known, and it was only last year that the researches of Dr. Hoek, exhibited in the Netherlands department of the Exhibition, threw a flood of light upon this point. These are the first of a more extensive series of investigations which are still in preparation, and which will treat of the embryology and the food of the oyster, the fixation of the spat, and the physical conditions under which the apparently very fertile oyster beds of the Eastern Scheldt are placed. These investigations have been undertaken and pursued for three summers consecutively by the Netherlands Zoological Society.

The exhibit in the Netherlands department is the only one in which the scientific side of the oyster question comes into the foreground. Highly interesting from the point of view of practical oyster culture are, however, two exhibits-one in the Norwegian, one in the British department, which we propose to describe somewhat more at length.

The Norwegian one is a bottle containing oysters from the small lake of Ostrawigtjen, near Soggendahl, on the south coast of Sweden. This lake, which is only about 800 feet long and 500 feet wide, with a depth of about six fathoms, may be regarded as a real "hothouse" for oyster culture, the temperature of the water being at the end of last April no less than $22^{\circ} \mathrm{C}$., whereas in winter the water at a depth of three fathoms never registers any lower temperature than $7^{\circ} \mathrm{C}$., the average bottom temperature in summer being $27^{\circ} \mathrm{C}$. Considering the latitude in which the lake is situated, these temperatures are indeed very remarkable, and have not yet been fully explained. Some would ascribe it to a most luxurious vegetation of Confervæ which is found in the lake, the partial decomposition and fermentation of which might increase the temperature. It is, however, open to question whether this confervoid vegetation must not perhaps be rather looked upon as an effect than as a cause of the bigh temperature.

This lake incloses a natural bed of oysters, and already at the end of March some of these oysters conluin ripe black spat. In the summer months the productivity of course greatly increases, and up to November (i.e. nearly nine months consecutively) ripe oysters with larvæ in their gills are met with.

It need not be said that this is a splendid collecting ground. The spat is collected on birch twigs which are suspended in the water on wires stretched over it.

In 1882 one thousand collectors were brought out, each having a surface of about sixteen square feet, and on these 730,000 young oysters were obtained, which were than transferred to natural beds in the fjord close to Stavanger.
If the oysters were left where they are they would certainly grow very quickly; oysters of one year sometimes attaining a size of six to seven centimetres. For several reasons, however, the transfer is regarded as more suitable for them.

A most curious fact concerning this lake remains yet to be told, viz. that it is situated $2 \frac{1}{2}$ feet above high-water mark; that it is separated from the sea by a dry tract of land with large boulders; and that only between September and March, when the weather is very rough, fresh sea water can gain access to the lake by the sea being thrown across this tract of land. At the opposite side of the lake a small rivulet of fresh water enters the lake.

A second "hothouse" for oyster culture appears to have been discovered only very lately; it is in most respects similar to the first; the depth is about $3 \frac{1}{2}$ fathoms; the temperature in Cctober was $18^{\circ} \mathrm{C}$., in April $2 \mathrm{I}^{\circ} \mathrm{C}$. It is situated at Vesetvig near Stavanger, on the Hardanger fjord.

The British exhibit, to which we would wish to call attention more especially, bears the name of Wootton, Isle of Wight. It consists of models of ponds devoted to the "basin culture" of oysters, essentially different in principle from "foreshore culture," which is at present more successful and more generally recommended.

"Basin culture" is nevertheless perhaps a future stage, when once the acute practical intelligence of the oysterculturist and the investigations of zoologists shall bave succeeded in reproducing the natural circumstances under which the oyster spat lives and thrives. At the conference on oyster culture held by Prof. Hubrecht, we were told that investigations more especially relating to basin culture were at the present moment being carried on in Holland. The result obtained in the Isle of Wight was this, that in the first year (1880) tive number of the spat obtained was about 25,000 , in the second year (I88I) 250,000 , and in the third (1882) r,500,000. Notwithstanding this successful commencement, the final results bave as yet remained far below the expectation, since only a comparatively small number could be brought to be marketable oysters. A difference between these experiments and those carried on in the Netherlands, which may perhaps prove to be one of fundamental importance, is this, that no contrivances have been made use of in the Isle of Wight to sufficiently aërate the sea water in the basins. Lack of oxygen may have been the principal cause of the great mortality of the spat. Moreover, a certain amount of sea water was let in and let out at favourable tides, and this must to a certain extent have interfered with the reliability of the results.

These experiments were carried on with oysters that were imported from the Arcachon beds.

The exhibits in the ostreicultural department by $\mathrm{Mr}$. Fell Woods, the well-known director of the South of England Oyster Company (Hayling Island), and by the Whitstable Oyster Company, likewise deserve attention. In both, specimens of shells of one-year-old oysters are shown, the occupants of which are said to have produced "black spat" at that early age. Even if these observations are well authenticated, it is nevertheless recognised that such facts are very rare (xceptions, and that generally at three years, and more profusely still at from four to six years, the maximum quantity of ripe spat is produced by the oysters, whose generative organs are most active at that age (cf. Hoek).

France has only a comparatively small exhibit; the implements used in oyster culture at Arcachon are there shown. The Netherlands are represented by a more complete collection, showing both dredging and collecting apparatus, so-called "hospitals," tiles, knives, \&c. Models of several oyster parks, partly constructed in old fortifications, and consequently having a very "defensive" aspect, are, moreover, exhibited, as well 
as maps and charts showing the way in which the foreshores, \&c., are leased by Government to individuals and companies interested in oyster culture. For further details concerning oyster culture in the Netherlands, we may refer the reader to the conference paper on this subject. On the whole oyster culture appears to be very successful in this country.

In the American department there is a large collection of the most various oyster-shells, as well as the model of a vessel occupied in dredging an oyster bed. "Culture" of oysters appears to be very little practised in that country up to the fresent day, the natural beds being as yet of a nearly inexhaustible richness, especially in the Southern States, where they are principally situated in the lagoons along the coast-line, and the oysters very often used as manure. Nor has the trade in these regions been developed to any extent. More northward Chesapeke Bay is the richest ground, and from thence oysters are transplanted along the coasts of the different Northern States, and at the same time brought into the market in enormous numbers. Together with the scientific investigations in the Netherlands, those in the United States, conducted by Brooks and Ryder, and those of Bouchon Beaudely in France, stand foremost as commendablc efforts to bring pure science to bear upon fishery problems of great practical importance.

\section{UNITED STATES COAST AND GEODETIC SURVEY $Y^{1}$}

THE author of this very important treatise states, in his preface, that he has attempted to give a sufficiently comprehensive account of the theory of projections to answer the requirements of the ordinary student of this subject. The literature of projections being extensive the work of the most eminent mathematicians - the author has contented himself with making such extracts from the great mass of papers, memoirs, \&c., which he deemed requisite for his purpose, giving, for further information, references to such original sources as are comparatively easy of access.

As the different conditions which projections for particular purposes have to satisfy are so wholly unlike, no general theory underlying the whole subject of projections can be given; it is therefore conveniently divided into several sections: and here the author mentions his obligations to M. Germain's most important "Traité des Projections" (Paris, 1865), which contains an account of almost every projection that has been invented. At the request of the Superintendent, Carlile P. Patterson, the treatise has been divided into two parts. The first part contains the mathematical theory of projections, while the second part contains merely such a sufficient account of the various projections as will enable the draughtsman to construct them.

The surface of the sphere being non-developable, the exact representation of even a portion of it upon a plane is impossible. Certain conditions can, however, be fulfilled which will render it sufficiently exact for any particular purpose. 'The areas may be proportionately preserved, in which case we have an equivalent projection; or the angles of small portions may be preserved, in which case we have an orthomorphic projection. The exigencies of any particular use for which a projection is designed give rise to a great number of other conditions corresponding to which projections have from time to time been invented: so that the history of projection has been peculiarly that of the solution of more or less independent problems : for a complete account of which the rcader is referred to M. D'Avezac's "Coup d'UEil historique sur la Projection des Cartes de Géographie" (Paris, 1863). x "United States Coast and Geodetic Survey" (Carlile 1". Patterson,
Supcrintendeni). A Treatise on Projections. By Thomas Craig. (Washingt $n$ : Government Pinting Office, 1882.)
The author has treated his subject under the following heads :-

I. Orthomorphic Projection.

II. Equivalent Projection.

III. Zenithal Projection.

IV. Projection by Development.

The first part of the volume treats of the mathematical theory, and is subdivided into nine sections. The first section contains a brief introductory account of the principal properties of conic sections and perspective projection - the most natural and simple method of representation. Sections II. and III. treat of methods of orthomorphic projection. Section IV. treats of projections by development; Section V. gives an account of zenithal, and Section VI. of equivalent projections. Students of these sections are presumed to have a fair acquaintance with the methods of ordinary analytic geometry and the elements of the differential and integral calculus. The next three sections are extremely general, and will require rather more extensive mathematical knowledge. These sections were designed to connect the particular problem of the plane representation of a sphere with the much more comprehensive methods of representation of one surface upon another, and to induce in the student, having a real interest in the general theory, a desire to consult the original memoirs for fuller information.

The second part of the volume, which treats of the construction of projections, docs not appear to require any detailed description; but as much of it is merely reprinted from the first part, the propriety of thus separating the "construction" from "theory" seems rather doubtful. The hook ends with thirty-one tables, nearly all extracted from the original memoirs of the writers on different parts of the subject of projections. In some cases, however, improved tables by other authors are given. Where the ellipticity of the earth has been taken into account the tables are given unchanged, as the effect of small changes of ellipticity would be almost inappreciable; and, moreover, we have in p. xiii. of the introduction the important statement that "The Urited States Coast and Geodetic Survey will undoubtedly soon be able to produce a much better value of the ellipticity than has yet been given."

Such are the contents of this valuable book we have endeavoured to describe. It presents, however, some signs of hasty arrangement and want of strict attention to the correction of the press, which will doubtless be removed from the next edition. Indeed the copy under notice would scarcely seem intended for publication in its present form. For instance, "The accompanying plates . ." mentioned in p. 230 are wanting; and we notice the following typographical errors, \&c. :-

Preface, p. x. Philosophical Magazine, 1865, should be 1862.

Preface, p. x., and Introduction, p. xiv. There are obvious errors in the title of Gauss's Memoirs.

Introduction, p. xiv. Phil. Trans. vol. 1. should be vol. L.

P. 80 , line 12 from bottom, for platting read plotting

Pp. 80 and 2 ro. The descriptions of Cassini's projection do not seem to be correct.

Pp. 81, 82, and 210 . The woodcuts defective.

P. 83. Curious crror in the numerator of the general expression for $\rho$.

Pp. 67 and 197. Woodcuts of Fig. I 3 not good.

Pp. $7 \mathrm{I}$ and 20I. Fig. I5, woodcuts require correction.

Pp. 76 and 206. Fig. 18, woodcuts not very good.

['. I49. In the denominator of the value of $m$ the power 2 of $(I \mp \epsilon \cos \omega)$ should be $\epsilon$. In the first term of the denominator of the value of $k, \sin ^{2} \omega_{1}$ should be $\sin ^{2} \frac{\omega_{2}}{2}$, and in the second term $\omega_{2}$ should be $\omega_{1}$. 